\title{
New Synbiotic Sweet Produced from Almond Skin and Some Probiotic Bacteria
}

\author{
MSc. Bashar A. Al-Akiqi ${ }^{1}$, Dr. Amer A. Al-Shikh Daher ${ }^{2}$ \\ ${ }^{1}$ Food Science Department, College of Agriculture, University of Baghdad \\ ${ }^{2}$ Professor, Food Science Department, College of Agriculture, University of Baghdad
}

\begin{abstract}
Several studies in recent years have shown the benefits deriving from the ingestion of probiotics, and a large number of products containing lactobacilli and bifidobacteria have been release to the markets. The aim of this study to show a symbiotic relationship (combination of probiotic and prebiotic) in a hand-made almond sweet and for the first time that combines the properties of both almond, as prebiotic, and Lactobacillus, as probiotic, to be served to the market as a healthy promoting foods. In this study we used Lb. Rhamnosus GG and Lb. Plantarum, well-recognized probiotic, with almond skin which was reaming after almond milk production which has a prebiotic characteristic, to build a synbiotic relationship. Also inulin was used, a well-recognized prebiotic, as another factor to maintain high viability and survival for both Lb. Rhamnosus GG and Lb. Plantarum during the procedure of processing and storage. Symbiotic sweet was sensory evaluation in food science department-College of Agriculture -University of Baghdad. The evaluation was conducted monthly, synchronous with microbiological assays. The result shown that no big different in the viability between Lb. Plantarum and Lb. Rhamnosus GG in the symbiotic sweet during the stored period in the refrigerator at ${ }_{4} C \pm 1$. But there's different between the control sweet and symbiotic sweet in total coliforms, yeasts and mold during the stored period and the Drop ratio for bacteria Lb. Plantarum and Lb. Rhamnosus GG at the end of the storage experiment was $8.5 \%$ and 7.6\%, respectively. And the synbiotic sweet hold all its sensory properties during the storage period on the contrary the control sweet expired and reached the stage of sensory rejection.
\end{abstract}

Keywords: Almond Skin. Probiotic. Synbiotic Sweet. Prebiotic

\section{Introduction}

Probiotic defined as live microorganisms that when administered in adequate amounts confer a health benefit on the host [1]. Lactobacillus is the most widely recognized as probiotic [2]. The use of probiotic in food production is not new, although in the early years it was used as food preservation then evolved towards benefits for health, such as reduction of cholesterol and enhance immune system [3]. The minimum recommended number of viable probiotic bacteria is $10^{7} \mathrm{cfu} / \mathrm{g}$ or $\mathrm{mL}$ of a product at the time of consumption [4]. Lb. Plantarum has significant antioxidant activities and also helps to maintain the intestinal permeability [5]. It is able to control the growth of gas producing microorganism in the intestines [6]. Lb. Plantarum increase hippocampal brain derived neurotropic factor which means it have a beneficial role in the treatment of depression [7]. Lactobacillus Rhamnosus $G G$ has the ability to stop allergic reactions to peanuts in $80 \%$ of children [8], and has been shown many other benefits in the prevention of rotavirus diarrhea in children, also it has a role in the prevention and treatment of various types of diarrhea both in children and in adults [9]. Lactobacillus GG reduces the risk of obtaining respiratory tract infections in children that attend daycare [10]. Although the dairy industry is the major sector involved in probiotic products, other food areas have recently become involved in probiotic products, Almond shows many nutritional and health benefit, Such as prebiotic compounds, prebiotic defined as "A nondigestible food ingredient which beneficially affects the host by selectively stimulating the growth and/or activity of one or a limited number of bacteria in the colon and thus improving host health" [11]. In order for a prebiotic to be effective, an ingredient must neither be hydrolyzed nor absorbed in the upper part of the gastrointestinal tract (GIT), Almond is very useful in producing symbiotic relationship and that's why it is used in this research. Prebiotic like inulin can be added easily to nut [12]. Inulin has a synergic effect on probiotic survival during processing and storage [13], also inulin can be extracted from a lot of food source (typically chicory root) or synthesized from a more fundamental molecule (typically sucrose) [14]. The consumption of almonds reduces the risk of heart diseases and reduces the risk of colon cancer [15], [16]. Almond skin is by- product from almond milk and blanching process. The high amount of antioxidants in the skin may be a result of natural evolution for the purpose of protecting the oil-rich almonds from oxidation by penetrating atmospheric oxygen [17]. Other health promoting compounds present in almond skins are polyphenols which have been shown to be protective agents against cancer and cardiovascular disease, the polyphenols present in almond skins are also active as antimicrobials against a range of food-borne pathogens. There is an increased effort in trying to avoid foods with chemical preservatives and this is manifested by the food industries growing interest in finding natural compounds with antimicrobial activity [18]. Dairy is a very nutritious substrate, which satisfies the nutritional requirements of fastidious LAB. But, expanding trend of vegan lifestyles, the issues of lactose intolerance, and the demand for low-fat and low-cholesterol foods have created a growing demand for non-dairy probiotic products [19]. Synbiotic is the coadministration of probiotic and prebiotics with the expectation that the prebiotics will enhance the survival and growth of the probiotics [20]. 


\section{International Journal of Science and Research (IJSR) \\ ISSN (Online): 2319-7064}

Index Copernicus Value (2015): 78.96 | Impact Factor (2015): 6.391

\section{Materials and Methods}

\subsection{Bacterial Strains and Culture Conditions}

The strains used were Lactobacillus rhamnosus $G G$ and Lactobacillus plantarum purchased from (NOVA, USA) well-recognized probiotics. One capsule of each $L b$. Rhamnosus $G G$ and of Lb.Plantarum individually was release in tuber contain $9 \mathrm{ml}$ of Man, Rogosa and Sharpe (MRS) broth (Oxoid, UK), and incubated at 37c for $24 \mathrm{~h}$, and was repeated 3 times. Then they were incubated individually in skim milk broth (12\% w/v) at $37 \mathrm{c}$ till curd is settled down, and repeated 3 times before it used.

\subsection{Ingredients for sweet Production}

Sweet was produced by using the following commercial ingredients: roasted almond peel $20 \%$ (obtained from almond milk processing), condensed sweeten milk 10\% (Dawn company, origin Singapore), inulin 10\% (Now company,

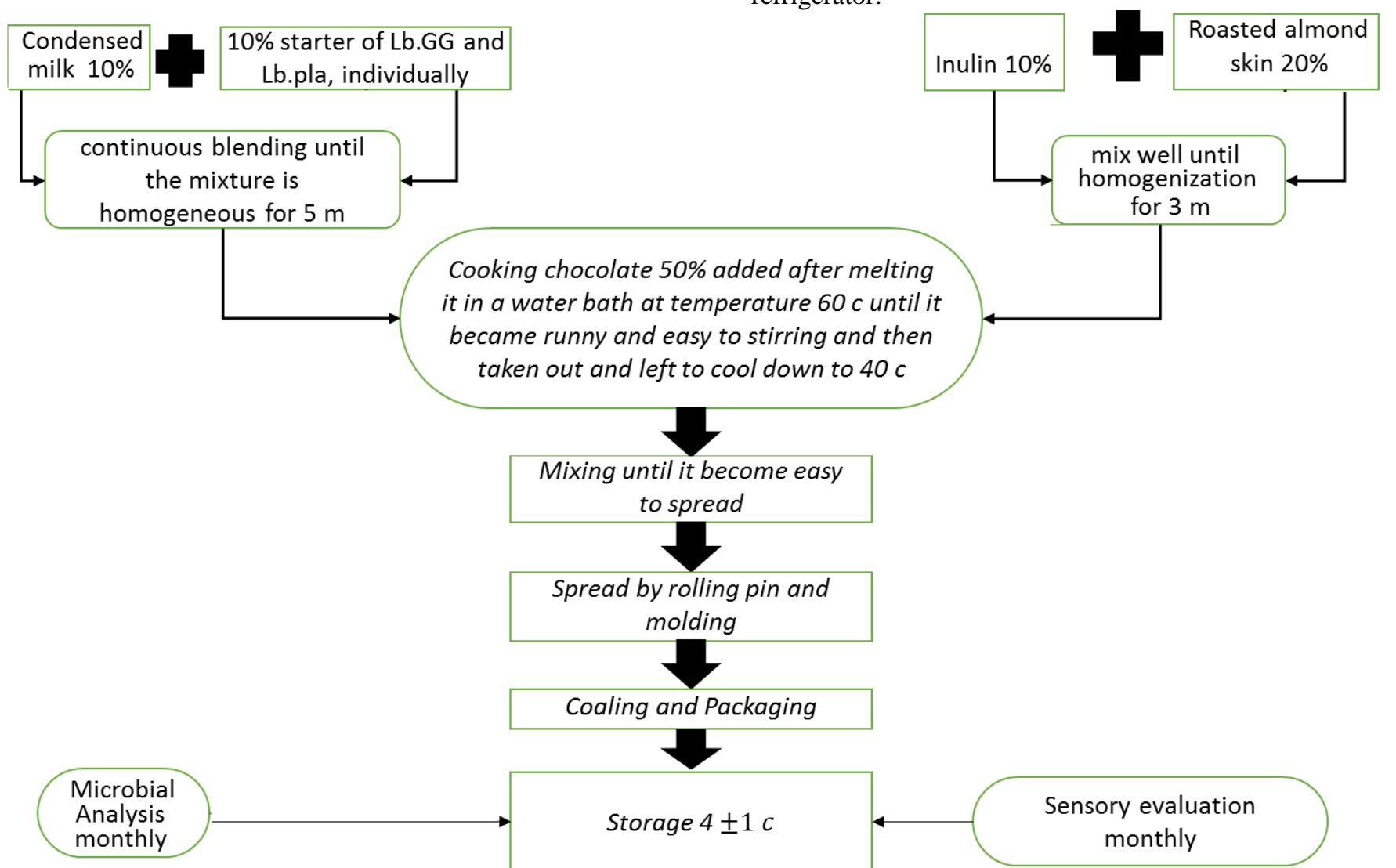

Figure 1: Synbiotic sweet procedure

origin USA), cooking chocolate 50\% (AL-wijdan company, origin Iraq).

\subsection{Synbiotic Sweet Production}

1) Solid ingredients Almond peel and inulin mix well until homogenization for $3 \mathrm{~m}$.

2) Liquid ingredients $10 \%$ starter of Lb.GG and Lb.pla add individually and condensed milk after good mixing and continuous blending until the mixture is homogeneous for $5 \mathrm{~m}$.

3) Cooking chocolate added after melting it in a water bath at temperature $60 \mathrm{c}$ until it became runny and easy to stirring and then taken out and left to cool down to $40 \mathrm{c}$ then it added to the mixture and kept mixing it until it became well-mixed.

4) Rolling pin use to spread the mixture with the desired thickness then put it in frozen for 10 minutes to become hard and easy to cut with knife or steel cutter mold.

5) The sweet wrapped with aluminum foil and stored in the refrigerator.

\section{Microbial Analysis}

Microbiological analyses were carried out on sweet samples synbiotic and control at $0,30,60,90,120$ days of refrigerator storage, according to the following procedure. Ten grams of each sweet was aseptically transferred into a sterile ceramic mortar, diluted with $90 \mathrm{ml}$ of sterile peptone water $(0.1 \% \mathrm{~W} / \mathrm{V})$, and homogenized for $6 \mathrm{~min}$ [21]. One milliliter of the third dilutions was used to obtain $10^{-3}$-fold serial dilutions, which were used for microbial counts. Both probiotic bacteria were counted under anaerobic conditions on MRS agar (Oxide, UK) for $48 \mathrm{~h}$ of incubation at $37 \mathrm{c}$, yeasts and mold were quantified on potato dextrose agar medium (Oxide, UK) for 5-7 days of incubation at $28 \mathrm{c}$. Total coliforms were counted on MacConkey agar (Oxide, UK) for 24 to $48 \mathrm{~h}$ of incubation at 37c. Total count were estimated (just for the control sweet) on nutrient agar (Oxide, UK) for $24 \mathrm{~h}$ of incubation at $37 \mathrm{c}$.

\section{Volume 6 Issue 7, July 2017 www.ijsr.net}




\section{International Journal of Science and Research (IJSR) ISSN (Online): 2319-7064}

Index Copernicus Value (2015): 78.96 Impact Factor (2015): 6.391

\section{Storage Experience}

To acknowledge the efficiency of symbiotic sweet in maintaining an appropriate viability number of probiotics was stored in the refrigerator at temperature of $4 \mathrm{c}$.

\section{Sensory Evaluation}

Symbiotic sweet was evaluated by 10 individuals' professors and postgraduate students in food science departmentCollege of Agriculture -University of Baghdad. The evaluation was conducted monthly, synchronous with microbiological assays. According to the form mentioned by Popov-Raljic [22]. Five terms were used: Color, Appearance, Hardness, Taste and Odor, with a scale from 1 to 10 for all the five terms. The samples stored at $4 \mathrm{c}$ and were removed from the refrigerator and drop out for $5 \mathrm{~min}$ at $25^{\circ} \mathrm{C}$ before sensory analysis.

\section{Results and Discussion}

\subsection{Starter Total Count}

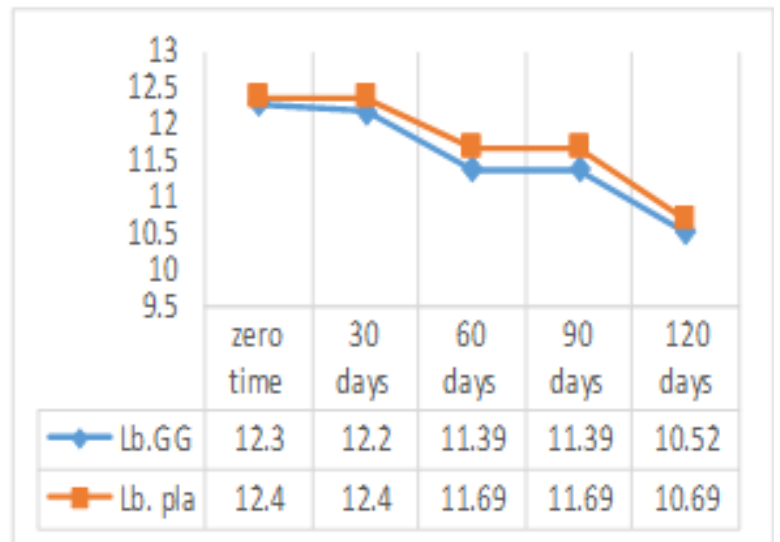

Figure 2: $L b . G G$ and Lb.pla count in synbiotic sweet during 120 days of storage

The result shown in figure 2 both probiotic bacteria $L b . G G$ and Lb.pla in synbiotic sweet count was extremely high 12.3 $\log / \mathrm{g}$ and $12.4 \mathrm{log} / \mathrm{g}$ respectively, due to the high amount of starter culture that were added and because of inulin (Probiotic) which stimulates the growth of both probiotic bacteria $L b . G G$ and Lb.pla. The result shown that even after 30 days of cold storage theirs no drop in the numbers of $L b . p l a$ and the drop ratio for $L b . G G$ was $1.6 \%$ this is because of inulin and the sweet matrix which provided protection to the probiotic bacteria during storage period in the refrigerator but at the end numbers of probiotic bacteria was decreased so slowly after 120 days of storage, where the rate of decline for $L b . G G$ was after $30,60,90$, and 120 days of storage 1.6, 6.6, 6.6 and $7.6 \%$ respectively, and for Lb.pla was 0, 5.7, 5.7 and $8.5 \%$ respectively. In that matter inulin can provide a high numbers and maintain good viability for probiotic bacteria and also the solid food matrix has an effective role for protection the probiotic during long storage period and within the human digestive system against extreme conditions compared to liquid matrix such as milk. Studies on probiotic chocolate by Possemiers have used a simulator of human GI tract (SHIME) to model the viability inside the GI tract, The observation is viability of chocolate is 5 -fold higher than the viability of milk inoculated with the same probiotics and inoculum size [23]. Other studies have suggested that the metabolism and utilisation of prebiotics by probiotics as a means of enhancing probiotic survival and proliferation [24], [25]. So non-dairy products particularly solid has its advantage in providing better viability and protection to the probiotic compared to dairy products especially which have liquid matrix like fermented milk, also lactobacillus spp. show more survival comparing with Bifidobacterium spp. [26].

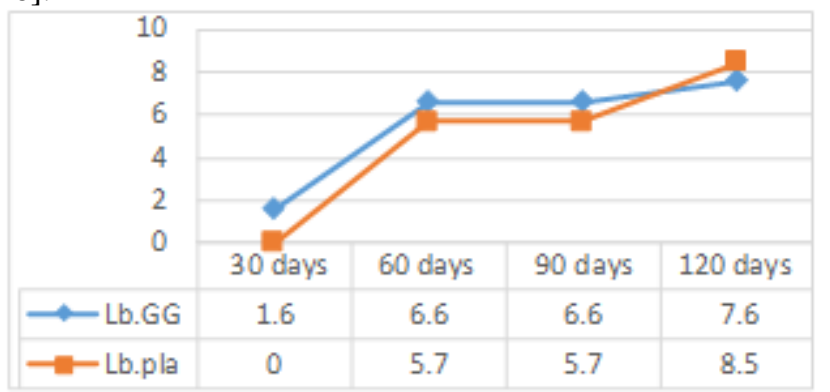

Figure 3: Drop ratio for Lb.GG and Lb.pla during storage period

\subsection{Coliforms test}

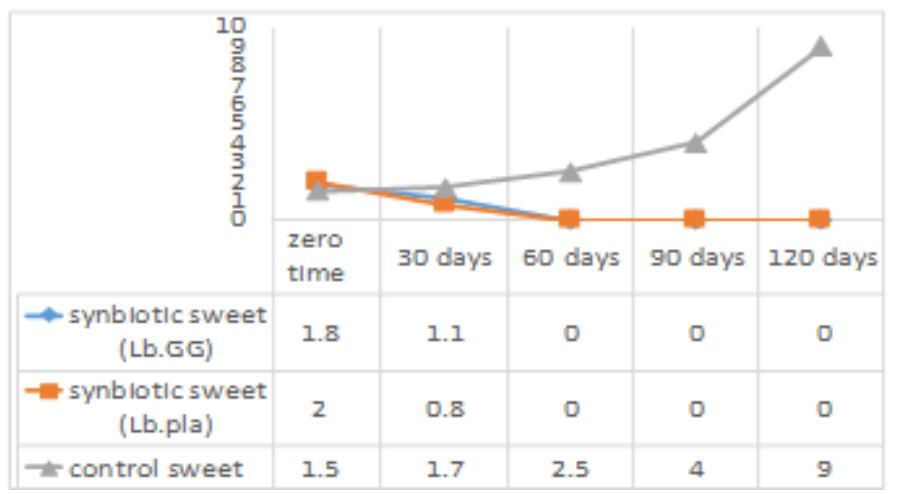

Figure 4: Coliforms count during storage period

The result show in figure 4 that total coliforms in synbiotic sweet that contain $L b . G G$ was $1.8 \mathrm{CFU} / \mathrm{g}$ at zero time and decline to $1.1 \mathrm{CFU} / \mathrm{g}$ and droop to zero after 60 days of storage. The same result shown in the synbiotic sweet that contain Lb.pla were total coliforms number decline form 2 $\mathrm{CFU} / \mathrm{G}$ at zero time to zero after 60 days of storage, while in the control sweet total coliforms number raised up from 1.5 $\mathrm{CFU} / \mathrm{g}$ to $9 \mathrm{CFU} / \mathrm{g}$ after 120 days of cold storage. The decline in the total coliforms number in the synbiotic sweet maybe to the antagonism activity for both probiotic bacteria $L b . G G$ and Lb.pla such as produce of hydrogen peroxide [27], bacteriocins [28], diacetyl \& acetaldehyde, which is antimicrobial agent against spoilage and pathogenic bacteria in foods and it has a more efficient effect against Gramnegative bacteria than Gram-positive bacteria [29].

\subsection{Mold and yeasts test}


International Journal of Science and Research (IJSR)

ISSN (Online): 2319-7064

Index Copernicus Value (2015): 78.96 | Impact Factor (2015): 6.391

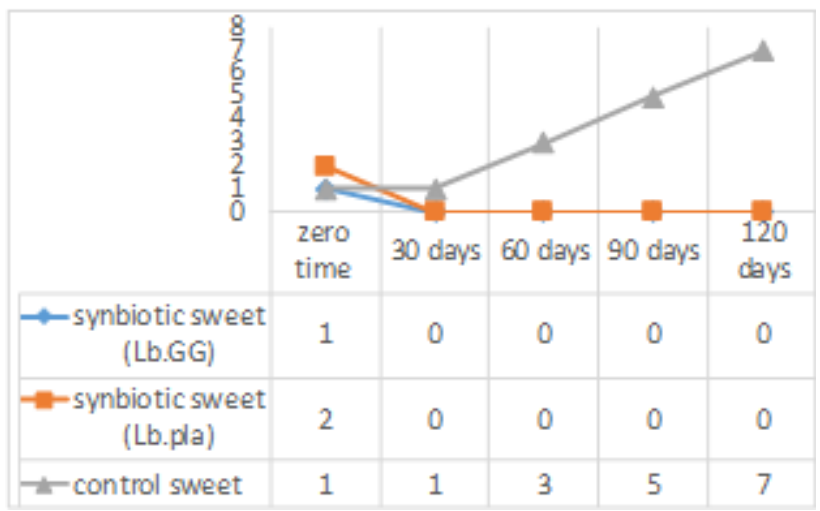

Figure 5: Mold and yeasts count during storage period

The result show in figure 5 the numbers of mold and yeasts in synbiotic sweet that contain Lb.GG and Lb.pla individually at zero time the count of mold and yeasts was $1 \mathrm{CFU} / \mathrm{g}$ and 2 $\mathrm{CFU} / \mathrm{g}$ respectively, and after 30 days of storage the numbers run-down to zero. While in the control sweet the numbers raised up from $1 \mathrm{CFU} / \mathrm{g}$ to $7 \mathrm{CFU} / \mathrm{g}$ after 120 days of cold storage. The decline in the mold and yeasts numbers in the synbiotic sweet maybe to the antagonism activity for both probiotic bacteria $L b . G G$ and Lb.pla such as produce of hydrogen peroxide, Bacteriocins, Diacetyl \& acetaldehyde, which is antimicrobial agent against mold and yeasts [30].

\subsection{Sensory Evaluation}

The result shown in table 1 that the Lb.GG and Lb.pla synbiotic sweet kept all five terms quality (Color, Appearance, Hardness, Taste and Odor) after 120 days of refrigerator storage, and the addition of $10 \%$ starter culture to the sweet didn't affect the five terms of sensory evaluation, comparing with the control sweet all sensory terms color, appearance, hardness, taste and odor was decreed during the storage period, droop from 10 to $7.3,9.4$ to $7,9.8$ to $6,9.2$ to $2,9.3$ to 5.6 respectively after 120 days of storage. That mean the control sweet was unacceptable after 60 days of storage, comparing with the synbiotic sweets the quality of all five terms kept excellent properties during the 120 days of cold storage period may be due to the antagonism activity by the probiotic bacteria which control the growth of spoilage microorganism like Coliforms, mold and yeasts [31], or the suppression of spoilage microorganism enzymes duo to the production of hydrogen peroxide, bacteriocins, diacetyl \& acetaldehyde [32]. Also the activity of probiotic dead cells show antagonism activity toward the spoilage microorganism [33], and the probiotic bacteria Lb.GG and Lb.pla show antioxidant activity that may keep the lipids from deterioration [34].

Table 1: Sensory evaluation of synbiotic sweet*

\begin{tabular}{|c|c|c|c|c|c|c|}
\hline Days & $\begin{array}{c}\text { Sweet } \\
\text { Treatment }\end{array}$ & Color & Appearance & Hardness & Taste & Odor \\
\hline \multirow{3}{*}{ Zero time } & Lb.GG & 9.7 & 10 & 9.3 & 10 & 9.1 \\
\cline { 2 - 7 } & Lb.pla & 9.5 & 10 & 9.6 & 9.8 & 9.7 \\
\cline { 2 - 7 } & Control & 10 & 9.4 & 9.8 & 9.2 & 9.3 \\
\hline \multirow{3}{*}{30 days } & Lb.GG & 9.9 & 10 & 9.4 & 10 & 9.4 \\
\cline { 2 - 7 } & Lb.pla & 9.4 & 10 & 9.6 & 10 & 9.9 \\
\cline { 2 - 7 } & Control & 9.4 & 9.2 & 9.5 & 9 & 9.3 \\
\hline \multirow{2}{*}{60 days } & Lb.GG & 9.7 & 10 & 9.6 & 10 & 9.6 \\
\cline { 2 - 7 } & Lb.pla & 9.4 & 10 & 9.7 & 10 & 9.7 \\
\hline
\end{tabular}

\begin{tabular}{|c|c|c|c|c|c|c|}
\hline & Control & 9 & 9.2 & 8.1 & 7.4 & 8.2 \\
\hline \multirow{3}{*}{90 days } & Lb.GG & 9.8 & 10 & 9.4 & 10 & 9.6 \\
\cline { 2 - 7 } & Lb.pla & 9.6 & 10 & 9.6 & 9.7 & 9.4 \\
\cline { 2 - 7 } & Control & 8.4 & 8.1 & 7.2 & 6 & 7.3 \\
\hline \multirow{3}{*}{120 days } & Lb.GG & 9.5 & 9.8 & 9.1 & 9.7 & 9.2 \\
\cline { 2 - 7 } & Lb.pla & 9.6 & 10 & 9.3 & 9.7 & 9.3 \\
\cline { 2 - 7 } & Control & 7.3 & 7 & 6 & 2 & 5.6 \\
\hline
\end{tabular}

* An average of 10 people were taken each time a sensory evaluation was performed

\section{References}

[1] FAO/WHO. Report on Joint FAO/WHO Expert consultation on evaluation of health and nutritional properties of probiotics in food including powder milk with live lactic acid bacteria, (2001).

[2] Y. Rivera-Espinoza and Y. Gallardo-Navarro. Non-dairy probiotic products. Food Microbiology 27(1): 1-11 (2010).

[3] N. Saad, C. Delattre, M. Urdaci, MJ. Schmitter and P. Bressollier. An overview of the last advances in probiotic and prebiotic field. Food Science and Technology 50(1): 1-16, (2013).

[4] Y. Sanz and J. Dalmau. Los probio' ticos en el Marco de la nueva normativa europea que regula los alimentos funcionales. Acta Pedia'trica Española 66: 27-31, (2008).

[5] C. Alison, C. Alan and M. Eva. Intestinal microbiota, probiotics and mental health: from Metchnikoff to modern advances: Part I - autointoxication revisited. Gut Pathogens 2013 5:5.

[6] M. Bixquert-Jiménez Selective. Colorectal cancer screening in average-risk populations. Vol. 101, N. ${ }^{\circ} 12$, pp. 821-829, (2009).

[7] AC. Bested, AC. Logan And ME. Selhub. Intestinal microbiota, probiotics and mental health: from Metchnikoff to modern advances: Part I autointoxication revisited. Gut Pathog. 2013 Mar 18; 5(1):5.

[8] S. Scott. Peanut allergies: Australian study into probiotics offers hope for possible cure, (2015).

[9] RB. Canaani, P. Cirillo, G. Terrin, L. Cesarano, ML. Spagnuolo, A. De Vincenzo, F. Albano, A. Passariello, G. De Marco, F. Manguso And A. Guarino. (2007). Isolate lactic acid bacteria from non-Malaysian chicken broiler chickens (Gallus Gallus) with a potential probiotic intestinal feeding broiler chickens. IIUM Engineering Journal, Vol. 12, No. 4, 2011: Special Issue on Biotechnology.

[10] I. Garaiova, J. Muchová, Z. Nagyová, D. Wang, Li JV., Z. Országhová, DR. Michael, SF. Plummer and Z. Duračková. Probiotics and vitamin $\mathrm{C}$ for the prevention of respiratory tract infections in children attending preschool: a randomized controlled pilot study. European Journal of Clinical Nutrition 69, 373-379, (2015)

[11] GR. Gibson and MB. Roberfroid. Dietary modulation of the colonic microbiota: Introducing the concept of prebiotics. J Nutr.125:1401-12, (1995).

[12]B. Neus, C. Maite, C. Amparo and Chelo Gonza'lezMartı'nez. Development of a non-dairy probiotic

\section{Volume 6 Issue 7, July 2017 www.ijsr.net}




\section{International Journal of Science and Research (IJSR) \\ ISSN (Online): 2319-7064}

Index Copernicus Value (2015): 78.96 | Impact Factor (2015): 6.391

fermented product based on almond milk and inulin. Food Science and Technology International 21(6) 440 453, (2014).

[13] RB. De Souza-Oliveira, P. Perego, A. Converti and MN. Oiliveira. The effect of inulin as prebiotic on the production of probiotic fiber-enriched fermented milk. International Journal of Dairy Technology 62(2): 195203, (2009).

[14]ND. Greg Kelly. Inulin-Type Prebiotics - A Review: Part 1. Alternative Medicine Review Volume 13, Number 4, (2008).

[15] S. Nishi, CW. Kendall, AM. Gascoyne, RP. Bazinet, B. Bashyam, KG. Lapsley, LS. Augustin, JL. Sievenpiper and DJ. Jenkins. Effect of Almond Consumption on the Serum Fatty Acid Profile: A Dose-Response Study. British Journal of Nutrition, 112, 1137-1146, (2014).

[16] M. Dharmasena. ASSESSMENT OF VIABILITY OF PROBIOTIC BACTERIA IN NON DAIRY FOOD MATRICES UNDER REFRIGERATION STORAGE. A Thesis Presented to the Graduate School of Clemson University In Partial Fulfillment of the Requirements for the Degree Master of Science Food, Nutrition, and Culinary Sciences. At Clemson University, South Carolina, USA, (2012).

[17] P. Chen, Y. Cheng, S. Deng, X. Lin, G. Huang and R. Ruan. Utilization of almond residues. Int J Agric \& Biol Eng, 2010; 3(4): 1-18.

[18] G. Mandalari, C. Bisignano, M. D’Arrigo, G. Ginestra, A. Arena. Antimicrobial potential of polyphenols extracted from almond skin. Lett Appl microbiol 51: 8389, (2010).

[19] G. Mandalari. Potential Health Benefits of Almond Skin. J Bioprocess Biotech 2:e110, (2012).

[20] J. Grimoud, H. Durand, C. Courtin, P. Monsan, F. Ouarné, V. Theodorou \& C. Roques. In vitro screening of probiotic lactic acid bacteria and prebiotic glucooligosaccharides to select effective synbiotics. Anaerobe, 16, 493-500, (2010).

[21] T. Di Criscio , A. Fratianni , R. Mignogna , L. Cinquanta , R. Coppola , E. Sorrentino, and G. Panfili. Production of functional probiotic, prebiotic, and synbiotic ice creams. J. Dairy Sci. 93:4555-4564 (2010).

[22] J. V. Popov-Raljić, G. J. Laličić-Petronijević , E. B. Dimić, S. V. Popov, V. B. Vujasinović, V. I. Blešić and J. M. Portić. Quality Parameters of Mixed Milk and Cocoa Spreads. Hem. ind. 67 (5) 781-793, (2013).

[23] S. Possemiers, M. Marzorati, W. Verstraete and T. V. de Wiele. Bacteria and Chocolate: A successful combination for Probiotic Delivery, International Journal of Food Microbiology, 141: 97-103, (2010).

[24] M. Saarela, K. Hallamaa, T. Mattila-Sandholm \& J. Matt. The effect of lactose derivatives lactulose, lactitol and lactobionic acid on the functional and technological properties of potentially probiotic Lactobacillus strains. International Dairy Journal, 13, 291-302, (2003).

[25] T. Wall, K. Bath, R. A. Britton, H. Jonsson, J. Versalovoc \& S. Ross. The early response to acid shock in Lactobacillus reuteri involves the ClpL chaperone and a putative cell wall altering esterase. Applied and Environmental Microbiology, 73, 3924-3935, (2007).
[26]K. Tanaka, M. Yano, M. Motoori, K. Kishi, I. Miyashiro, M. Ohue, H. Ohigashi, T. Asahara, K. Nomoto \& O. Ishikawa. Impact of perioperative administration of synbiotics in patients with esophageal cancer undergoing esophagectomy: A prospective randomized controlled trial. Surgery, 152(5), 832-842, (2012).

[27]A. C. Ouwehand and S. Vesterlund. Antimicrobial Components from Lactic Acid Bacteria. In S. Salminen, Von Wright, A., Ouwehand, A. (Ed.), Lactic Acid Bacteria: Microbiological and Functional Aspects. New York: Marcel Dekker, (2004).

[28]A. S. Naidu. Natural Food Antimicrobial Systems, Director, Center For Antimicrobial Research Department of Food, Nutrition \& Consumer Sciences California State Polytechnic University Pomona, California, and CRC Press LLC, USA, (2000).

[29] J. M. Jay. Modern Food Microbiology. 5th Ed. New York: Van No Strand Reinhold, (1996).

[30] G. Reid, J. Jass, M. T. Sebulsky \& J. K. McCormick. Potential uses of probiotics in clinical practice. Clinical Microbiology Reviews, 16, 658-672, (2003).

[31] TR. Abrahamsson, G. Sinkiewicz, T. Jakobsson, M. Fredrikson, B. Björkstén. Probiotic lactobacilli in breast milk and infant stool in relation to oral intake during the first year of life.J Pediatr Gastroenterol Nutr. 49(3):34954, (2009).

[32]B. Bandyopadhyay, C. Narayan- Mandal. Probiotics, Prebiotics and Synbiotics -In Health Improvement by Modulating Gut Microbiota: The Concept Revisited. International Journal of Current Microbiology and Applied Biosciences, 3: 410-420(2014).

[33] SR. Konstantinov, EJ. Kuipers, MP. Peppelenbosch. Functional genomic analyses of the gut microbiota for CRC screening.Nature Reviews Gastroenterology \& Hepatology. 10:741-745, (2013).

[34]F. Leroy and L. De Vuyst. Lactic acid bacteria as functional starter cultures for the food fermentation industry. Trends Food Sci. Technol. 15: 67-78, (2004).

\section{Volume 6 Issue 7, July 2017 www.ijsr.net}

